\title{
Evaluation of a commercial Erns-capture ELISA for detection of BVDV in routine diagnostic cattle serum samples
} Jaruwan Kampa*1,2, Karl Ståhl3,4, Lena HM Renström ${ }^{4}$ and Stefan Alenius ${ }^{1}$

Address: ${ }^{1}$ Department of Clinical Sciences, Swedish University of Agricultural Science (SLU), SE-75007, Uppsala, Sweden, ${ }^{2}$ Faculty of Veterinary Medicine, Khon Kaen University, 40002, Thailand, 3Department of Biomedical Sciences and Veterinary Public Health, SLU, SE-75007, Uppsala, Sweden and ${ }^{4}$ National Veterinary Institute (SVA), SE-75007, Uppsala, Sweden

Email: Jaruwan Kampa* - jaruwan.kampa@kv.slu.se; Karl Ståhl - karl.stahl@bvf.slu.se; Lena HM Renström - lena.renstrom@sva.se; Stefan Alenius - stefan.alenius@kv.slu.se

* Corresponding author

Published: 13 March 2007

Acta Veterinaria Scandinavica 2007, 49:7 doi:10.1/86/1751-0147-49-7

This article is available from: http://www.actavetscand.com/content/49/1/7

(c) 2007 Kampa et al; licensee BioMed Central Ltd.

This is an Open Access article distributed under the terms of the Creative Commons Attribution License (http://creativecommons.org/licenses/by/2.0), which permits unrestricted use, distribution, and reproduction in any medium, provided the original work is properly cited.
Received: 28 November 2006

Accepted: 13 March 2007

\begin{abstract}
Background: Bovine viral diarrhoea virus (BVDV) is an important pathogen in cattle. The ability of the virus to cross the placenta during early pregnancy can result in the birth of persistently infected (PI) calves. These calves shed the virus during their entire lifespan and are the key transmitters of infection. Consequently, identification (and subsequent removal) of PI animals is necessary to rapidly clear infected herds from the virus. The objective of this study was to evaluate the suitability of a commercial $E^{\text {rns }}$-capture ELISA, in comparison to the indirect immunoperoxidase test (IPX), for routine diagnostic detection of BVDV within a control programme. In addition, the effect of passive immunity and heat-inactivation of the samples on the performance of the ELISA was studied.
\end{abstract}

Methods: In the process of virus clearance within the Swedish BVDV control programme, all calves born in infected herds are tested for virus and antibodies. From such samples, sent in for routine diagnostics to SVA, we selected 220 sera collected from 32 beef herds and 29 dairy herds. All sera were tested for BVDV antigen using the Erns ELISA, and the results were compared to the results from the IPX used within the routine diagnostics.

Results: All I 30 samples categorized as virus negative by IPX were tested negative in the ELISA, and all 90 samples categorized as virus positive were tested positive, i.e. the relative sensitivity and specificity of the ELISA was $100 \%$ in relation to IPX, and the agreement between the tests was perfect.

Conclusion: We can conclude that the Erns ELISA is a valid alternative that has several advantages compared to IPX. Our results clearly demonstrate that it performs well under Swedish conditions, and that its performance is comparable with the IPX test. It is highly sensitive and specific, can be used for testing of heat-inactivated samples, precolostral testing, and probably to detect PI animals at an earlier age than the IPX. 


\section{Background}

Bovine viral diarrhoea virus (BVDV) is a widely spread cattle pathogen with a significant economic impact on cattle production [1]. The virus interferes with reproductive and immunological functions and causes subsequent losses due to reproductive disorders and impaired herd performance $[2,3]$. Based on phylogenetic comparison, the virus can be classified into two genotypes: BVDV-1 and BVDV2. Whereas BVDV-1 has a world-wide distribution, BVDV2 appears to be highly prevalent only in North America $[4,5]$ and relatively rare in other continents $[6,7]$.

The ability of the virus to cross the placenta during the first trimester of pregnancy can result in the birth of immunotolerant and persistently infected (PI) calves. These PI calves shed the virus during their entire lifespan and are the key transmitters of virus in an infected herd [8] and responsible for maintaining BVDV infections in cattle populations [9]. Consequently, identification (and subsequent removal) of PI animals is necessary to rapidly clear infected herds from the virus.

To identify PI animals, virus isolation on primary bovine cells, followed by immuno-enzyme staining is regarded as the "gold standard" method. The indirect immunoperoxidase (IPX) test is a standard method to detect BVDV in several diagnostic laboratories and is used in the BVDV control programme in Sweden [10]. During the course of this programme, the IPX test has shown to be highly effective for identifying PI animals $[11,12]$. However, the IPX test is time consuming and requires a high investment both in personal training and laboratory equipment, which is why antigen-capture ELISAs have been increasingly used since the early 1990's. The NS2/3-capture ELISA detects BVDV in leukocytes and tissue samples using specific affinity monoclonal antibodies (MAb) against the NS2/3 protein, and has been successfully used to identify PI animals in BVDV control programmes in Norway and in the Shetland islands $[13,14]$. Recently, an antigen ELISA that uses MAbs against the Erns glycoprotein has been developed to detect BVDV. This structural protein is secreted from infected cells during virus replication and can be detected directly in serum which allows user friendly and high throughput testing and gives it the potential to be a diagnostic antigen $[15,16]$.

The objective of this study was to evaluate the suitability of a commercial Erns-capture ELISA (E ${ }^{\text {rns }}$ ELISA; HerdCheck BVDV antigen/Serum Plus, IDEXX Scandinavia AB, Österbybruk, Sweden.), in comparison to IPX, for routine diagnostic detection of BVDV within a control programme. In addition, the effect of passive immunity and heat-inactivation of the samples on the performance of the ELISA was studied.

\section{Methods \\ I. Selection of samples}

I.I. Samples from the field

In the process of virus clearance within the Swedish BVDV control programme, all calves born in infected herds are tested for virus and antibodies at an age of 12 weeks, or older. Blood samples are collected in sterile 5-ml vacutainer tubes and sent for analysis to the National Veterinary Institute (SVA), Uppsala, Sweden. From each herd detected as infected, one virus positive sample is selected for further analysis and genotyping of the infecting strain [17]. So far, only BVDV-1 has been detected in Sweden.

From samples sent in for routine diagnostics to SVA between September 2002 and February 2003, we selected 220 sera collected from 32 beef herds and 29 dairy herds throughout Sweden. According to the results from the IPX used within the routine diagnostics [18] 90 of the sera were considered virus positive and 130 virus negative. All sera were kept at $-20^{\circ} \mathrm{C}$ until analyzed by the Erns ELISA.

\section{I.2. Samples from PI calves with or without passive immunity}

To study the influence of passive immunity on the performance of the ELISA and IPX, we selected serum samples from nine PI calves born after a previously described experimental infection of pregnant heifers [19]. In total, we tested 23 samples collected between day 0 (i.e. immediately after birth and before intake of colostrum) and day 11 post partum (Table 1 ). Of the nine calves, five (calves 1-5) were given colostrum free from BVDV antibodies, and four (calves 6-9) were given colostrum from their respective antibody positive dams. Antibody titres were determined in all sera using a commercial indirect ELISA (BVDV-Ab SVANOVIR ${ }^{\mathrm{TM}}$, SVANOVA Biotech AB, Uppsala, Sweden).

\section{I.3. Heat inactivated sera}

To study the influence of heat inactivation, we selected a subset of 20 sera ( 10 virus positive and 10 virus negative) out of the 220 samples previously selected from the routine diagnostics. Each sample was divided in two parts, and one was heat inactivated at $56^{\circ} \mathrm{C}$ for 90 minutes before further analysis. Heat inactivated and non-heated sera were then tested in parallel with the $\mathrm{E}^{\text {rns }}$ ELISA.

\section{Diagnostic methods}

\section{I. Detection of BVDV by IPX}

The 220 samples from the field and the 23 samples from PI calves were also tested for BVDV by IPX. The test was carried out on 96-well plates using low-passage bovine turbinate cells. Serum $(20 \mu \mathrm{l})$ was added to each of four wells before the addition of $100 \mu$ l of cell suspension. Positive and negative control sera were run on each plate. The test plates were incubated for 4 days in $5 \% \mathrm{CO}_{2}, 37^{\circ} \mathrm{C}$. Plates were fixed and dried, then stained with immu- 
Table I: Results from testing for BVDV in sera collected between days 0 and I I post partum from nine PI calves born after experimentally infected heifers, using a commercial Erns-capture ELISA (HerdCheck BVDV antigen/Serum Plus, IDEXX Scandinavia AB, Österbybruk, Sweden.) and the indirect immunoperoxidase test (IPX).

\begin{tabular}{|c|c|c|c|c|c|}
\hline PI calf no. & Age (days) & Antibody titre & $\begin{array}{l}\text { Virus detection } \\
\text { IPX }\end{array}$ & $\mathrm{E}^{\text {rns ELISA }}{ }^{\mathrm{a}}$ & $(C O D)$ \\
\hline \multirow[t]{3}{*}{ I } & 0 & $<1: 10$ & - & + & $(3.32)$ \\
\hline & 2 & $<1: 10$ & + & + & $(2.96)$ \\
\hline & 7 & $<1: 10$ & + & + & $(2.70)$ \\
\hline \multirow[t]{3}{*}{2} & 0 & $<1: 10$ & + & + & $(2.99)$ \\
\hline & 2 & $<1: 10$ & + & + & $(3.52)$ \\
\hline & 3 & $<1: 10$ & + & + & $(3.42)$ \\
\hline \multirow[t]{4}{*}{3} & 0 & $<1: 10$ & - & + & $(3.21)$ \\
\hline & 2 & $<1: 10$ & + & + & $(3.00)$ \\
\hline & 7 & $<1: 10$ & + & + & $(2.97)$ \\
\hline & 11 & $<1: 10$ & + & + & $(2.52)$ \\
\hline 4 & 0 & $<1: 10$ & + & + & (3.33) \\
\hline \multirow[t]{2}{*}{5} & 0 & $<1: 10$ & - & + & (3.56) \\
\hline & 2 & $<1: 10$ & + & + & (3.26) \\
\hline \multirow[t]{4}{*}{6} & 0 & $<1: 10$ & + & + & (3.27) \\
\hline & 2 & $\mathrm{I}: 250$ & - & - & $(0.16)$ \\
\hline & 5 & $1: 250$ & - & + & (3.29) \\
\hline & 7 & $1: 10$ & - & + & (3.28) \\
\hline 7 & 2 & $\mathrm{I}: 250$ & - & + & $(0.48)$ \\
\hline \multirow[t]{2}{*}{8} & 4 & $1: 1250$ & - & - & $(0.29)$ \\
\hline & 6 & $\mathrm{I}: 250$ & - & + & $(1.58)$ \\
\hline \multirow[t]{3}{*}{9} & 2 & $\mathrm{I}: 1250$ & - & + & $(2.92)$ \\
\hline & 7 & $1: 1250$ & - & - & $(0.04)$ \\
\hline & 9 & $1: 1250$ & - & - & $(0.07)$ \\
\hline
\end{tabular}

Calves I-5 were given colostrum free from BVDV antibodies, and calves 6-9 were given colostrum from their respective antibody positive dams. Samples collected day 0 were taken before intake of colostrum. BVDV antibody titres were determined using a commercial indirect ELISA (SVANOVA Biotech AB, Uppsala, Sweden) in dilutions I:10-I:I250.

a Samples with COD > 0.30 as measured by the Erns ELISA were considered positive

noperoxidase as described by Meyling [18], using a polyclonal bovine anti-BVDV serum (BVD virus positive control serum, VLA, Weybridge, UK) to detect the virus. The presence of red-brown cytoplasmic staining in any of the wells exposed to the specific anti-BVDV antibody denoted a positive result.

\subsection{Detection of BVDV by antigen ELISA}

All samples were tested for BVDV antigen using the Erns. capture ELISA according to the manufacturer's instructions. Briefly, provided detection antibodies were added to all wells of a microtitre plate wells coated with Erns $^{\text {rn }}$ MAbs. Positive and negative control sera were added to appropriate duplicate wells, and the serum samples (50 $\mu \mathrm{l})$ then added to the remaining wells. The plate was incubated for 2 hours at $37^{\circ} \mathrm{C}$, before washing and addition of conjugate and substrate. The optical density values (ODs) were measured at $450 \mathrm{~nm}$, and the corrected optical densities (CODs) of samples and positive control then calculated by subtracting the mean $\mathrm{OD}$ for the negative controls from obtained OD $\left(\mathrm{COD}=\mathrm{OD}^{\text {obtained }}-\right.$ mean
OD negative controls). Samples with COD> 0.30 were classified as positive.

\subsection{Detection of antibodies}

The antibody titres of the sera from the nine PI calves were determined using the commercial indirect ELISA in dilutions $1: 10$ to $1: 1250$. The ELISA was performed according to the instructions of the manufacturer. The COD values from the indirect ELISA $\left(\mathrm{COD}^{\mathrm{Ab}}\right)$ were calculated before interpretation of the result by subtracting the OD for control antigen from obtained $\mathrm{OD}\left(\mathrm{COD}^{\mathrm{Ab}}=\mathrm{OD}^{\text {obtained }}\right.$ $\left.\mathrm{OD}^{\text {control}}\right)$. Antibody titres were determined as the highest dilution with $\mathrm{COD}^{\mathrm{Ab}} \geq 0.2$.

\section{Statistical analysis}

The sensitivity (Se) and specificity (Sp) of the Erns ELISA were calculated in relation to the IPX test, and the degree of agreement between the tests was estimated by the kappa ( $k$ ) ratio. To estimate the effect of heat inactivation on the performance of the ELISA we evaluated the repeatability of the test before and after heat inactivation of the 
samples using the concordance correlation coefficient (CCC) [20] and Bland-Altman plot [21].

\section{Results}

\section{Samples from the field}

The results from the testing of the 220 sera, selected among samples sent in to SVA, are summarized in Table 2. All 130 samples categorized as virus negative by IPX were tested negative in the ELISA, and all 90 samples categorized as virus positive were tested positive, i.e. the relative Se and Sp of the ELISA was 100\% in relation to IPX, and the agreement between the tests was perfect $(k=1.0)$. The frequency distribution of COD values can be seen in Figure 1. Out of 90 samples considered as virus positive according to the IPX test results, 89 had COD values well above the cut-off $(>1.2)$.

\section{Samples from PI calves with or without passive immunity} The results of the testing of the 23 samples from PI calves are given in Table 1. Out of 14 samples with antibody ELISA titres $<1: 10,14$ were tested positive in the Erns ELISA and 11 in the IPX. The three samples that were falsely classified as negative by the IPX were all collected day 0 post partum, i.e. before intake of colostrum. Among the 9 samples with antibody titres ranging between 1:10 and $1: 1250,5$ samples were tested positive in the $E^{\text {rns }}$ ELISA and none in the IPX.

\section{Heat inactivation}

The agreement between results obtained before and after heat inactivation can be seen in Figure 2. There was a perfect agreement of the interpretations of the test results obtained before and after heat inactivation, and the CCC was calculated to 0.99. The BA plot (not shown) indicated that $95 \%$ of the differences between heat-inactivated and non-heated samples fell in the range of -0.39 and +0.22 units.

\section{Discussion}

The identification of PI animals (for subsequent elimination) is an essential element in any BVDV control programme, and depends on accurate diagnostic tests, i.e. tests with high sensitivity and specificity that have been thoroughly evaluated for routine diagnostic use. Moreover, for testing of large series of samples it is desirable that a test is user friendly and allows automation. Even though the IPX test currently used in Sweden has shown to be efficient for detection of PI animals, it is evident that the $\mathrm{E}^{\text {rns }}$ ELISA have several advantages: it is independent of cell cultures, gives a test result within a few hours and is relatively inexpensive both to establish and run [22]. In addi-

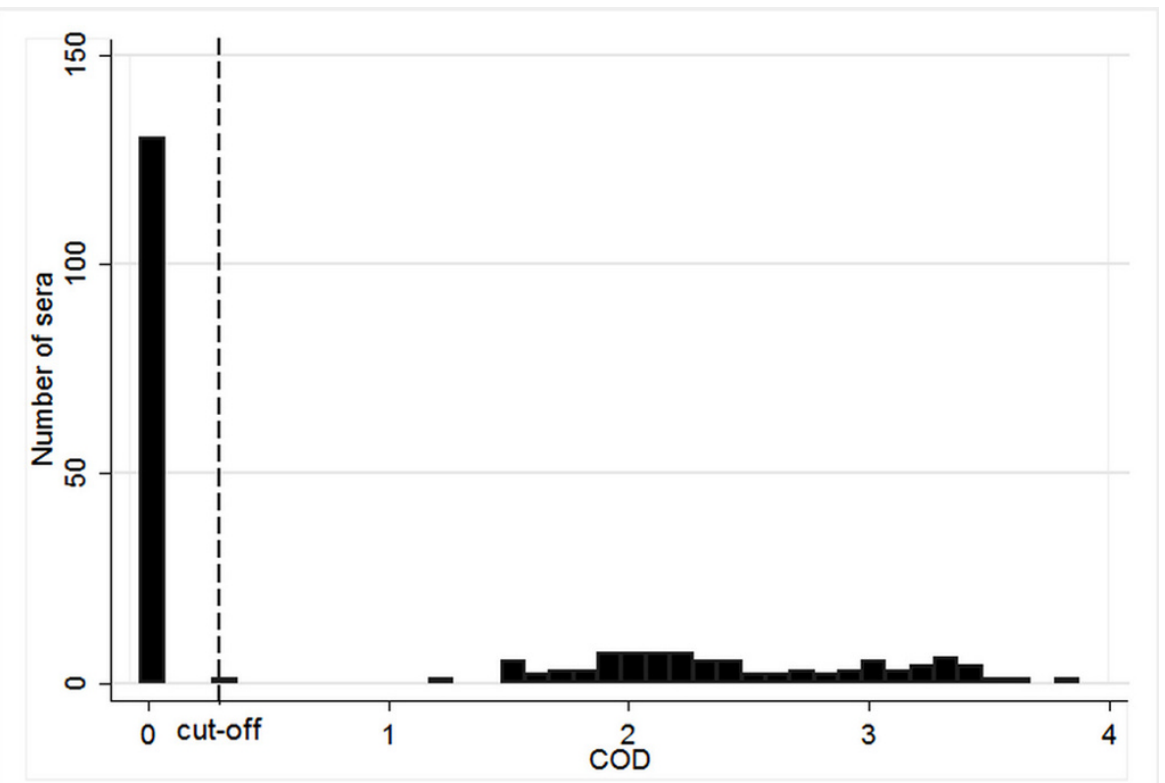

Figure I

Frequency distribution diagram of corrected optical density (COD) values as measured by a commercial Erns-capture ELISA (HerdCheck BVDV antigen/Serum Plus, IDEXX Scandinavia AB, Österbybruk, Sweden) in 90 bovine sera considered as virus positive and 130 bovine sera considered as virus negative according to the indirect immunoperoxidase test used within the Swedish BVDV control programme. All sera were selected among samples sent for routine diagnostics to the National Veterinary Institute, Uppsala, Sweden, between September 2002 and February 2003. ELISA results with COD >0.30 were considered positive. 
Table 2: Results from testing of 220 Swedish bovine serum samples using a commercial Erns-capture ELISA (HerdCheck BVDV antigen/Serum Plus, IDEXX Scandinavia AB, Österbybruk, Sweden.), and comparison with results obtained with the indirect immunoperoxidase (IPX) test.

\begin{tabular}{llcc}
\hline Erns ELISA & IPX & Negative & Positive \\
& Mean COD (range) & 130 & 0 \\
Negative & $0.00(-0.027-0.03)$ & 0 & 90 \\
Positive $^{\mathrm{a}}$ & $2.34(0.31-3.78)$ & 0 & \\
\hline
\end{tabular}

a ELISA results with COD $>0.30$ were considered positive

tion, our results clearly demonstrate that it performs well under Swedish conditions, i.e. for detection of BVDV-1, and that its performance is comparable with the IPX test. There was a perfect agreement between the results from the two tests, and the separation between COD values from negative and positive samples was good. Out of 220 samples, 219 had COD values either well below or well above the cut-off. However, one sample, considered as virus positive according to the IPX test results, had a COD value close to the cut-off, and there are a number of possible explanations for this result. Firstly, as with the major- ity of BVDV antigen ELISAs, this Erns ELISA has been developed for the identification of PI animals. Whereas virus titres in PI animals normally range between $10^{2.2}$ and $10^{6} \mathrm{TCID}_{50} / \mathrm{ml}$, titres during transient infections have been reported to be as low as $10^{0.9}$ [23-25]. It is likely that the detection level of the IPX test is lower than that of the ELISA, and it is possible that this serum sample originated from a transiently infected animal. Secondly, although PI animals normally have high virus titres, these may, as previously mentioned, show a wide range. Consequently, it is also possible that this serum sample originated from a PI

\section{Note: Data must overlay dashed line for perfect concordance}

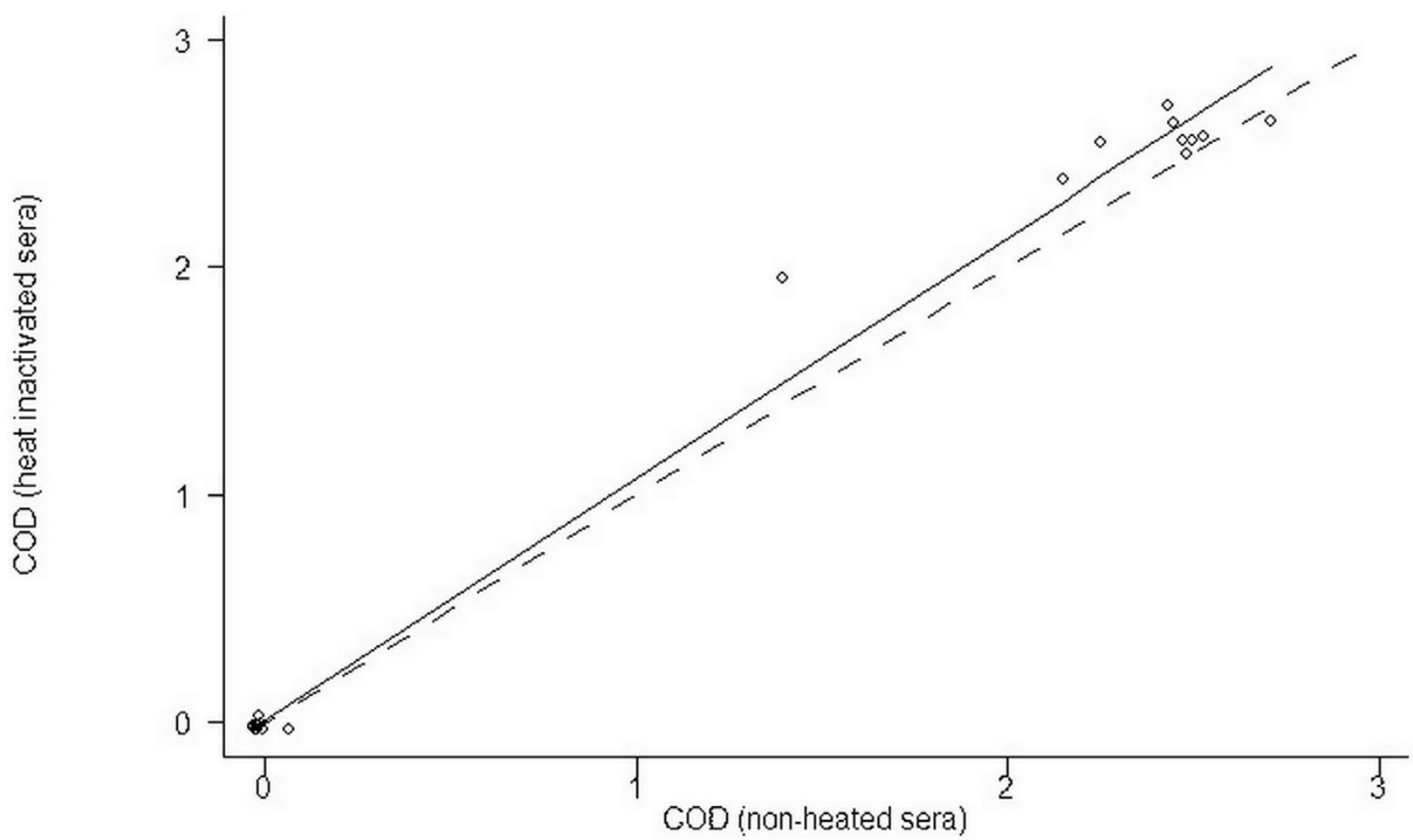

Figure 2

Agreement between COD values obtained with a commercial Erns-capture ELISA (HerdCheck BVDV antigen/Serum Plus, IDEXX Scandinavia AB, Österbybruk, Sweden.) from testing of 20 bovine serum samples (I0 virus positive and I0 virus negative) before and after heat inactivation at $56^{\circ} \mathrm{C}$ for 90 minutes $(C C C=0.99)$. 
animal, but that the virus titer was low, and close to the detection limit of the ELISA.

Because the Erns ELISA, unlike the IPX test used, is based on MAbs and has been developed and validated for detection of BVDV-1 and BVDV-2, it is probably not as broadly reactive as the IPX. It has been shown not to detect some closely related border disease virus strains [26], and may, consequently, also miss atypical pestiviruses. This should be kept in mind, as there are indications that atypical pestiviruses are already circulating in cattle populations $[27,28]$.

It was demonstrated that both tests might fail to detect a large proportion of PI calves in the presence of persisting maternal antibodies, confirming results from previous studies[29,30]. However, whereas the IPX test gave false negative results also in the presence of low antibody titres, the Erns ELISA detected BVDV in three out of four sera with antibody titres up to 1:250, indicating that the $E^{\text {rns }}$ ELISA is less influenced by passive immunity. We could also observe that the IPX test, unlike the Erns ELISA, gave false negative results in three out of five newborn PI calves sampled before intake of colostrum. This has been observed previously and is hard to explain (Rønsholt, personal communication), but is one of several reasons for which precolostral sampling is not practiced within the Swedish BVDV control programme.

In addition, it was demonstrated that the performance of the Erns ELISA was not influenced by heat inactivation, which can be an advantage in laboratories where sera are often subject to several analyses and therefore heat-inactivated by routine.

\section{Conclusion}

Based on these results we can conclude that the Erns ELISA is a valid alternative to the IPX test. It is highly sensitive and specific, can be used for testing of heat-inactivated samples, precolostral testing, and probably to detect PI animals at an earlier age than the IPX. However, it should be kept in mind that this ELISA, unlike the IPX, uses MAbs, and that it therefore is less likely to detect atypical pestivirus strains.

\section{Competing interests}

The author(s) declare that they have no competing interests.

\section{Authors' contributions}

JK and SA took part in all aspects of the study, including study design, laboratory analysis, interpretation of the results, and drafting of the manuscript. KS participated in interpretation of the results and drafting of the manuscript. LR participated in study design and revision of the manuscript. All authors have read and given final approval of the version to be published.

\section{Acknowledgements}

We would like to thank Gunnel Svedlund for technical assistance. This project was supported by the Swedish Farmers' Foundation for Agricultural Research (SLF; Proj.no. 0330007). Jaruwan Kampa is holder of a scholarship from the Royal Thai Government.

\section{References}

I. Houe H: Economic impact of BVDV infection in dairies. Biologicals 2003, 3 I(2): I37-143.

2. Moerman A, Straver PJ, de Jong MC, Quak J, Baanvinger T, van Oirschot JT: A long term epidemiological study of bovine viral diarrhoea infections in a large herd of dairy cattle. Vet Rec 1993, 132(25):622-626.

3. Houe H: Epidemiological features and economical importance of bovine virus diarrhoea virus (BVDV) infections. Vet Microbiol 1999, 64(2-3):89-107.

4. Fulton RW, Saliki JT, Confer AW, Burge LJ, d'Offay JM, Helman RG, Bolin SR, Ridpath JF, Payton ME: Bovine viral diarrhea virus cytopathic and noncytopathic biotypes and type $I$ and 2 genotypes in diagnostic laboratory accessions: clinical and necropsy samples from cattle. J Vet Diagn Invest 2000, I2(I):33-38.

5. Evermann JF, Ridpath JF: Clinical and epidemiologic observations of bovine viral diarrhea virus in the northwestern United States. Vet Microbiol 2002, 89(2-3): I29-139.

6. Wolfmeyer A, Wolf G, Beer M, Strube W, Hehnen HR, Schmeer N, Kaaden OR: Genomic (5'UTR) and serological differences among German BVDV field isolates. Arch Virol 1997, I 42(10):2049-2057.

7. Sakoda Y, Ozawa S, Damrongwatanapokin S, Sato M, Ishikawa K, Fukusho A: Genetic heterogeneity of porcine and ruminant pestiviruses mainly isolated in Japan. Vet Microbiol 1999, 65(I):75-86.

8. Bolin SR: Control of bovine virus diarrhoea virus. Rev Sci Tech 1990, 9(1):163-171.

9. Brownlie J: The pathways for bovine virus diarrhoea virus biotypes in the pathogenesis of disease. Arch Virol Suppl 1991, 3:79-96.

10. Lindberg A: Contrywide eradication of BVDV- How can it be done?: 7-8 March 2005; Wellington, New Zealand. 2005:53-62.

II. Lindberg AL, Alenius S: Principles for eradication of bovine viral diarrhoea virus (BVDV) infections in cattle populations. Vet Microbiol 1999, 64(2-3): 197-222.

12. Hult L, Lindberg A: Experiences from BVDV control in Sweden. Prev Vet Med 2005, 72 (1-2): 143-8; discussion 215-9.

13. Sandvik T, Krogsrud J: Evaluation of an antigen-capture ELISA for detection of bovine viral diarrhea virus in cattle blood samples. J Vet Diagn Invest 1995, 7(1):65-7I.

14. Synge BA, Clark AM, Moar JA, Nicolson JT, Nettleton PF, Herring JA: The control of bovine virus diarrhoea virus in Shetland. Vet Microbiol 1999, 64(2-3):223-229.

15. Brownlie J, Thompson I, Curwen A: Bovine virus diarrhoea virus - strategic decisions for diagnosis and control. In Practice 2000:176-187.

16. Kuhne S, Schroeder C, Holmquist G, Wolf G, Horner S, Brem G, Ballagi $A$ : Detection of bovine viral diarrhoea virus infected cattle--testing tissue samples derived from ear tagging using an Erns capture ELISA. J Vet Med B Infect Dis Vet Public Health 2005, 52(6):272-277.

17. Ståhl K, Kampa J, Baule C, Isaksson M, Moreno-López J, Belák S, Alenius S, Lindberg A: Molecular epidemiology of bovine viral diarrhoea during the final phase of the Swedish BVD-eradication programme. Prev Vet Med 2005, 72(I-2): 103-108.

18. Meyling A: Detection of BVD virus in viremic cattle by an indirect immunoperoxidase technique. In Recenct advances in virus diagnosis Haggue:Martinus Nijhoff Publishers; 1984:37-46.

19. Lindberg A, Niskanen R, Gustafsson H, Bengtsson B, Baule C, Belak S, Alenius S: Prenatal diagnosis of persistent bovine viral diar- 
rhoea virus (BVDV) infection by detection of viral RNA in fetal fluids. Vet $J$ 2002, 164(2): $15 I-155$.

20. Lin LI: A concordance correlation coefficient to evaluate reproducibility. Biometrics 1989, 45(I):255-268.

21. Bland JM, Altman DG: Statistical methods for assessing agreement between two methods of clinical measurement. Lancet 1986, I(8476):307-3I0.

22. Sandvik T: Selection and use of laboratory diagnostic assays in BVD control programmes. Prev Vet Med 2005, 72(I-2):3-6.

23. Bolin SR, McClurkin AW, Cutlip RC, Coria MF: Response of cattle persistently infected with noncytopathic bovine viral diarrhea virus to vaccination for bovine viral diarrhea and to subsequent challenge exposure with cytopathic bovine viral diarrhea virus. Am J Vet Res 1985, 46( (12):2467-2470.

24. Janmaat A, Burgess GW: Natural transmission of adventitious bovine viral diarrhoea virus in cattle under experimentation. In Aust Vet J Volume 65. Australian Veterinary Journal ; 1988:1 190-191.

25. Bolin SR, Ridpath JF: Differences in virulence between two noncytopathic bovine viral diarrhea viruses in calves. $\mathrm{Am} J$ Vet Res 1992, 53(I I):2157-2163.

26. Schroeder C, Nettleton P, Toomik R, Ballagi A: Current data on detection of BVDV and BVD infection using HerdCheck BVDV antigen ELISAs: 9-I 3 November 2003; Bangkok, Thailand. ; 2003.

27. Schirrmeier H, Strebelow G, Depner K, Hoffmann B, Beer M: Genetic and antigenic characterization of an atypical pestivirus isolate, a putative member of a novel pestivirus species. J Gen Virol 2004, 85(Pt I 2):3647-3652.

28. Ståhl K, Kampa J, Alenius S, Persson Wadman A, Baule C, Aiumlamai S, Belák S: Natural infection of cattle with an atypical 'HoBi'like pestivirus -Implications for BVD control and for the safety of biological products. Veterinary Research in press.

29. Palfi V, Houe H, Philipsen J: Studies on the decline of bovine virus diarrhoea virus (BVDV) maternal antibodies and detectability of BVDV in persistently infected calves. Acta Vet Scand 1993, 34(I): 105-107.

30. Brinkhof J, Zimmer G, Westenbrink F: Comparative study on four enzyme-linked immunosorbent assays and a cocultivation assay for the detection of antigens associated with the bovine viral diarrhoea virus in persistently infected cattle. Vet Microbiol 1996, 50(I-2): I-6.

\section{Publish with Bio Med Central and every scientist can read your work free of charge}

"BioMed Central will be the most significant development for disseminating the results of biomedical research in our lifetime. "

Sir Paul Nurse, Cancer Research UK

Your research papers will be:

- available free of charge to the entire biomedical community

- peer reviewed and published immediately upon acceptance

- cited in PubMed and archived on PubMed Central

- yours - you keep the copyright

Submit your manuscript here:

http://www.biomedcentral.com/info/publishing_adv.asp
BioMedcentral 